\title{
O mercado habitacional e o processo de gentrificação em cidades latino-americanas: um estudo exploratório no bairro de Boa Viagem, Recife-PE
}

\author{
The housing market and gentrification process in Latin American cities: \\ an exploratory study in Boa Viagem neighborhood, Recife-PE
}

Fernando Pontual de Souza Leão Júnior ${ }^{[a, b]}$, Cristóvão de Souza Brito ${ }^{[a, b]}$

${ }^{[a]}$ Universidade de Pernambuco (UPE), Caruaru, PE, Brasil
${ }^{[b]}$ Faculdade Integrada de Pernambuco (FACIPE), Recife, PE, Brasil

\section{Resumo}

O espaço da cidade é o lócus de ação dos agentes do mercado imobiliário habitacional, e suas ações são indutoras do processo de diferenciação demográfica nas cidades. A ideia de que a ação do mercado estabelece uma nova lógica de ocupação urbana é o objeto da análise realizada neste trabalho, o qual pretende compreender a relação entre a ação do mercado habitacional no município de Recife-PE e o processo de gentrificação decorrente dela. Foi realizado um estudo de caso no bairro Boa Viagem, principal foco de atuação do mercado habitacional formal. 0 trabalho é de natureza descritiva e utiliza uma modelagem estatística de regressão linear para estabelecer um entendimento conciso acerca da relação entre algumas variáveis demográficas do bairro e a ação do mercado habitacional. Os resultados indicaram que houve um gradativo processo de elevação das variáveis socioeconômicas nos bairros, a qual foi superior ao mesmo processo nos bairros onde a ação do mercado foi menor ou inexistente. A hipótese de que a ação do mercado habitacional estabelece um processo de segmentação e diferenciação demográfico-espacial foi confirmada, denotando a ocorrência de mudança imobiliária e o consequente processo de gentrificação.

Palavras-chave: Gentrificação. Mercado habitacional. América Latina. Recife-PE.

\section{Abstract}

The city territory is the locus of housing market agents' actions, which are inducers of the cities' demographic differentiation process. This study aimed to analyze the idea that the market action establishes a new logic of urban occupation. Our goal is to understand the relationship between the action of the housing market in the city of Recife-PE and the process of gentrification resulting therefrom. We conducted a case study in the Boa Viagem neighborhood, the main focus of the formal housing market. The work is descriptive in nature and uses a statistical model of linear regression to establish a concise understanding of the relationship between some demographic variables of the neighborhood and the housing market action. The results indicated a gradual rising of the socioeconomic variables in these neighborhoods, and this increase was higher than in

FPSLJ é doutor em Desenvolvimento Urbano, prof. adjunto da Universidade de Pernambuco, prof. titular da Faculdade Integrada de Pernambuco, e-mail: fpontualjunior@gmail.com

CSB é doutor em Desenvolvimento Urbano, prof. adjunto da Universidade de Pernambuco, prof. titular da Faculdade Integrada de Pernambuco, e-mail: cristovaos.brito@gmail.com 
neighborhoods where the market action was minor or nonexistent. The hypothesis that the housing market action establishes a process of segmentation and demographic-spatial differentiation was confirmed, denoting the occurrence of real estate change and consequent process of gentrification.

Keywords: Gentrification. City, housing market. Latin America. Recife-PE.

\section{Introdução}

A primeira década do século XXI foi marcada pelo crescimento econômico do Brasil e pela consequente participação mais efetiva do setor privado como agente de transformação de sua socioeconomia. $\mathrm{O}$ ciclo de crescimento observado no período determinou um gradativo interesse dos investidores internos e externos no mercado brasileiro. A continuação da estabilidade política, associada ao crescimento da economia nacional, elevou no ano de 2008 o grau de investimento do país, significando maior nível de segurança para os investidores e aumentando ainda mais o interesse no mercado brasileiro.

Nesse cenário positivo, as políticas de distribuição de renda e de desenvolvimento regional conduzidas pelo governo federal aumentaram o tamanho do mercado, inserindo novos consumidores, o que levou à maximização da capacidade de consumo do mercado interno. 0 mercado imobiliário, assim como outros setores da economia, beneficiou-se das políticas e intensificou sua atuação com o suporte, muitas vezes, de investimentos estrangeiros. Paiva (2007) considera que, além dos fatores citados, a constituição de novos mecanismos de financiamento para o setor imobiliário, como os condomínios, os certificados de recebíveis e os fundos de investimento imobiliário, também contribuiu de modo significativo.

Não obstante o crescimento tenha ocorrido em todo o país, algumas regiões experimentaram novas modalidades de investimentos e novos investidores, que antes não demonstravam interesse nessas regiões. Entre elas deve-se atribuir grande destaque à região Nordeste. O crescimento acumulado no período (de 1999 a 2009) foi de 33\% para o Brasil, $42 \%$ para a região Nordeste e 39\% para o Estado de Pernambuco. Os índices superiores de crescimento possibilitaram certa recuperação das principais economias da região. Entre os que mais se beneficiaram das altas taxas de crescimento está Pernambuco, um Estado que teve sua importância econômica maior associada à cultura da cana-de-açúcar, que entrou em declínio a partir do início do século XX e chegou praticamente à total desarticulação nos tempos atuais.

A partir de 2002, houve uma retomada no processo de industrialização no Estado, principalmente na zona litorânea (Zona da Mata Norte e Zona da Mata Sul), com a consolidação do complexo portuário de SUAPE, na Mata Norte, e, posteriormente na Mata Sul, com a chegada dos complexos automobilísticos e o anúncio da criação do polo industrial de hemoderivados (que não chegou a se consolidar).

O setor imobiliário, ao perceber a pujança econômica do Estado, passou a desenvolver grandes empreendimentos, principalmente em Recife, Pernambuco, capital e mais importante município do Estado e uma das mais significativas para a região Nordeste. Recife possui 1.537.704 habitantes, distribuídos em 94 bairros (IBGE, 2010a, 2010b). A concentração das atividades imobiliárias, em boa parte do seu território, deve-se às condições positivas em relação à infraestrutura e aos serviços de que dispõe na qualidade de sede metropolitana. À medida que o município passou a apresentar uma inserção gradativa na economia nacional, percebeu-se a chegada de agentes econômicos antes não observados no seu limitado leque de produtores, os quais passaram a atuar em composição com incorporadores, construtores e investidores da localidade ou em voos solo.

Contudo, a ação descoordenada do mercado, somada à aquiescência ou mesmo inoperância do poder público local, conduziu a uma urbanização até certo ponto caótica, concentrando uma grande quantidade de empreendimentos em uma área pequena do município, na qual o bairro Boa Viagem desponta como local de intensa polarização por parte dos produtores. Um fator agravante remete às limitações territoriais do município, o qual se constitui em uma das menores capitais do país, totalizando apenas $219 \mathrm{~km}^{2}$, sendo uma parte significativa desse território situada em regiões de morro ou de alagadiços. Como mostra o destaque em vermelho do mapa da Figura 1, o bairro Boa Viagem representa uma pequena faixa de terra, com aproximadamente $7 \mathrm{~km}^{2}$ entre o 


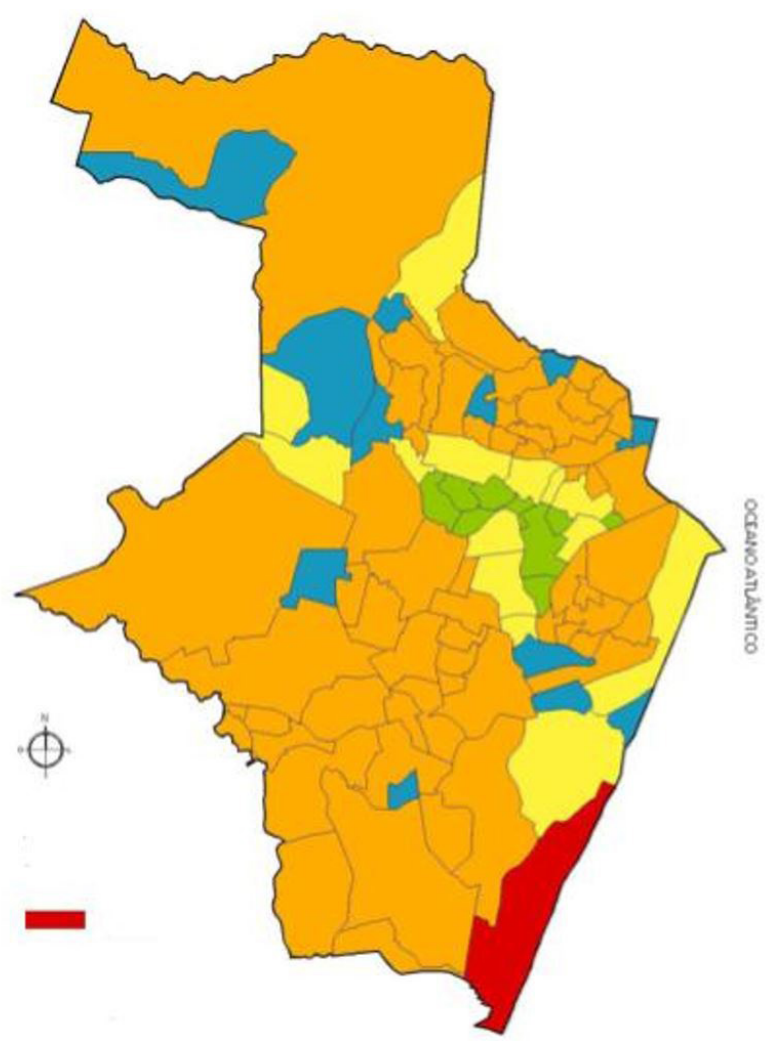

Figura 1 - Representação do bairro Boa Viagem no mapa de Recife-PE Fonte: Leão (2012).

Oceano Atlântico e uma área de manguezais. Após a década de 1960, iniciou-se um processo de transição do bairro de uma estância de veraneio de famílias abastadas da cidade e vila de pescadores para o local mais procurado para empreendimentos imobiliários de alto padrão. De acordo com Leão (2012), o bairro Boa Viagem, sozinho, representa mais de $50 \%$ dos lançamentos imobiliários residenciais formais do município de Recife.

Esse processo de ocupação pelo mercado residencial foi mais intenso no bairro Boa Viagem e nos bairros inseridos nas áreas situadas à margem direita do Rio Capibaribe, perfazendo um conjunto de 12 bairros, que posteriormente vieram a sofrer uma ação regulatória mais expressiva por parte do poder público municipal, a qual implicou na imposição de gabarito construtivo para as edificações (Recife, 2001). Como consequência, os bairros Boa Viagem e Casa Amarela receberam dos produtores imobiliários maiores investimentos a partir de então. Para Boa Viagem, as limitações construtivas impostas a bairros mais nobres, tais como Graças, Espinheiro, Aflitos, Casa Forte e Parnamirim, entre outros, intensificaram ainda mais o interesse do capital imobiliário, após a vigência da lei, já que não foi afetado pela nova regulação. As atividades imobiliárias nas áreas da zona norte do município passaram a se concentrar nos bairros vizinhos, enquanto a área de Boa Viagem e proximidades teve um avanço ainda mais intenso. 0 presente trabalho objetiva analisar o processo de consolidação do mercado habitacional no bairro Boa Viagem e seu impacto nas variáveis socioeconômicas de sua população entre 1991 e 2010.

\section{Metodologia}

O presente trabalho é de natureza descritiva, pois busca compreender um fenômeno a partir da observação, avaliação e comparação de um conjunto de variáveis. A abordagem de pesquisa foi predominantemente quantitativa e se utilizou de métodos estatísticos para inferir sobre os comportamentos das referidas variáveis. 0 trabalho se caracteriza como um estudo de caso, visto que se limitou a analisar, no âmbito do município de Recife, a específica dinâmica espacial no bairro Boa Viagem, no qual se faz observar fortemente um processo de gentrificação, cujas externalidades se irradiam para bairros menos interessantes à atividade imobiliária de médio e alto padrão.

Para realização do estudo, foram utilizados a base de dados do Índice de Velocidade de Vendas (IVV/FIEPE) e, para a análise dos dados demográficos, os dados dos Censos do IBGE (1991, 2000, 2010a, 2010b).

A variável dependente "característica demográfica do bairro" é representada por meio de indicadores de população, educação, renda, faixa etária e acesso à saneamento. A variável independente é o IVV divulgado pela FIEPE, que mensura o nível de atividade imobiliária no município de Recife. A série histórica do IVV envolve o período compreendido pelos anos de 2000 a 2010. Os dados foram submetidos a uma análise de variância (ANOVA), o que permitiu inferir sobre a relação entre os fenômenos analisados, como mostram os resultados apresentados no subitem pertinente.

\section{Fundamentação teórica}

A conjunção de variáveis que respondem pela substituição gradual do elemento humano na ocupação dos espaços urbanos, tais como renda, nível de 
escolaridade, idade, entre outros, vem produzindo um fenômeno bem recente nos estudos da demografia, o qual vem sendo denominado gentrificação. A cunhagem do termo teve sua origem na Inglaterra, a partir de estudos realizados pela socióloga Ruth Glass, em 1964 (Glass, 2013). 0 cenário desses estudos foi a cidade de Londres, onde foi detectada a ocorrência de um processo de transição ou de substituição da população em alguns de seus espaços urbanos, o qual foi associado, evolutivamente, a um "enobrecimento" do lócus residencial.

Tal reconhecimento implicou em reconhecer a gentrificação como um processo de mudança imobiliária, na medida em que o conceito de espaços enobrecidos subentendia altercações que se vinculam a uma congérie de fenômenos indissociáveis (escolaridade, renda e faixa etária) de uma mudança do padrão social de uma localidade. Em seu sentido lato, portanto, o termo não comportava uma conotação de excludência social que atualmente a ele se associa, uma vez que se originava de políticas públicas emanadas de uma atuação concertada pela gestão pública, pelo ativismo social e pelo empreendedorismo urbano (produtores imobiliários, comerciantes, produtores culturais etc.), no sentido de propiciar um novo olhar sobre espaços e áreas degradados da cidade.

Com o passar do tempo, os atributos virtuosos, que estavam vinculados ao conceito, foram maculados pelas relações conflituosas estabelecidas ao ser evidenciado que a combinação gravosa decorrente de disparidades de renda, educação, cultura e perfis de consumo diferenciados viria a produzir segmentação e exclusão social.

Ao caráter de externalidade positiva imaginado pelos policy makers se incorporou um dissenso entre os stakeholders, parte deles avaliando a gentrificação positivamente e outra parte percebendo-a de modo negativo. Como consequência, nos anos de 1980, surgiu um movimento que buscou redirecionar as vertentes desvirtuadoras da gentrificação, que foi denominado placemaking (cujos fundamentos remontam às ideias de Jane Jacobs, nos anos de 1960), por contemplar os mesmos propósitos de revitalização de espaços degradados, mas cuidando de eliminar os riscos da elitização, ao encarnar a máxima de que a restauração e a ressignificação de espaços só eliminam tais riscos quando todas as partes interessadas são ouvidas (Jacobs, 2011).
Infelizmente, a clivagem evoluiu com o tempo, e, em se tratando de políticas públicas urbanas vivenciadas em países em desenvolvimento, como é o caso do Brasil, observa-se, em matizes variados, a prevalência desabonadora dos impactos da gentrificação e de suas especificidades, especialmente no que se refere às experiências realizadas em Recife.

Cabe registrar que, a despeito das digressões e diferenciações que o conceito vem recebendo ao longo do tempo, tanto em uma perspectiva originalmente marxista de estudiosos, como Neil Smith, quanto em uma visão pós-moderna, como a de David Harvey, cabe situar a preocupação do presente estudo com a percepção de que o conceito mais atual de gentrificação se descole daquele inicialmente vinculado ao estudo das mudanças no padrão do desenvolvimento urbano de cidades situadas em países de capitalismo avançado. Trata-se, no estudo em tela, de percebê-lo como um fenômeno que transpôs a visão hermética que lhe deu origem, ao se colocar em um patamar que o consolida, no entender de Neil Smith, como uma "estratégia urbana global", decorrente tanto da transnacionalização do capital financeiro quanto do próprio fundamento do rent gap de que trata Karl Marx (Smith, 2006).

Tal mudança se caracteriza, diante de um pressuposto parcialmente duvidoso, como sendo de melhoria qualitativa na composição populacional de tais espaços, haja vista que o termo gentry equivaleria, em português, a "bem-nascido", dados os critérios já elencados de maior poder aquisitivo e maior nível de escolaridade observados nessa transição. Na realidade, tal como conceituado por Bataller (2000 apud Silva et al., 2008, p. 85), a gentrificação

[...] consiste en una serie de mejoras físicas o materiales y cambios inmateriales - económicos, sociales y culturales que tienen lugar en algunos centros urbanos viejos, los cuales experimentan una apreciable elevación de su status.

Entretanto, o caráter virtuoso que se intentou associar às referidas mudanças imobiliárias revela facetas que traduzem as vicissitudes associadas à gentrificação. Segundo Smith (2007), a mais perversa dessas vicissitudes se associa à promoção de um desenvolvimento desigual, que se relaciona a uma congérie de fatores implícitos aos processos de reestruturação urbana, os quais são supervenientes a tais processos: (a) a suburbanização e o surgimento de um diferencial 
de renda (rent gap); (b) a desindustrialização das economias capitalistas avançadas e o crescimento do emprego no setor de serviços; (c) a centralização espacial e a simultânea descentralização do capital; (d) a queda na taxa de lucro e os movimentos cíclicos do capital; e (e) as mudanças demográficas e nos padrões de consumo.

Embora o escopo deste artigo não se objetive por ser uma proposta de aprofundar as causalidades implícitas ao fenômeno da mudança imobiliária e da gentrificação, parece ser clara a necessidade de justificar, de modo abreviado, os fatores elencados por Smith (2007) como inerentes à reestruturação urbana. Nesse sentido, a financeirização da economia e as articulações políticas entre Estado e mercado ensejam uma maior influência deste último nas decisões referentes à ocupação dos espaços urbanos (Paiva, 2007; Leal, 2003; Smith, 2007).

Tal necessidade se contextualiza minimamente ao estrito objetivo de verificar se o fenômeno analisado por estudiosos, como o próprio Smith (2007), Jager (1986), Zukin (2000), entre outros, enquadra-se como um descritor teoricamente abalizado para o reconhecimento da ocorrência de um fenômeno similar em curso em Recife. É importante salientar que, nas economias de capitalismo tardio, como é o caso do Brasil, as relações público-privadas apresentam características diferentes, de modo que as influências do mercado nas políticas públicas se dão de forma efetiva, de maneira implícita ou explícita, principalmente $\mathrm{o}$ aspecto do empreendedorismo urbano, que passou a predominar na gestão pública no âmbito brasileiro (Leal, 2003). Por meio dos mecanismos de regulação/desregulação urbanísticos, as ações do setor imobiliário são facilitadas ou não, conforme a natureza da relação entre os setores públicos e privados (Leão \& Brito, 2011). Destarte, um diferencial de renda assume papel de relevância na mudança imobiliária, haja vista que se caracteriza como uma consequência de um concomitante movimento de centralização e de descentralização do capital e da mobilidade da população no espaço geográfico que decorre da própria movimentação e da necessidade de mudança nas expectativas do capital.

Entretanto, na realidade terceiro-mundista ou de subdesenvolvimento, como é o caso de cidades brasileiras e, em especial, de Recife, o conceito de subúrbio se matiza e se multiplica em virtude de se tratar de uma extensão territorial totalmente urbana, ou seja, desprovida de zona rural e, portanto, sem condição de se assemelhar ao conceito americano, ou inglês, ou, ainda, primeiro-mundista de subúrbio. Cá prevalecem as razões inversas que caracterizam a suburbanização: os bairros mais distantes da parte central são redutos das classes de renda média baixa e baixa.

Por outro lado, os assentamentos de moradia tipificados como subnormais (IBGE, 2010a, 2010b) caracterizam a prioridade que as famílias de baixa renda ou de quase nenhuma renda expressam ao estarem próximas à agitação das áreas mais centrais, as quais representam a possibilidade de rendimentos marginais (bicos), sujeitando-as a ocupar as áreas de alagadiços, morros, mangues e regiões ribeirinhas.

Há de se destacar que o conceito de suburbanização, no caso de Recife, assenta-se em uma lógica de motivações socioeconômicas similares ao processo de suburbanização norte-americano, à exceção do fato de que ela ocorre como uma dinâmica de curso forçado que leva as famílias de menor poder aquisitivo a migrar para os bairros de renda mais baixa. Isso se dá sempre que ocorre um expressivo aumento da produtividade de trabalho em seus bairros de origem, com os consequentes impactos da elevação do padrão de renda e da elevação do custo de vida. Nesse sentido, é inevitável evitar uma sinonímia generalizada ao se tratar de suburbanização e de periferização.

Pode-se perceber que os diferenciais de renda delineiam uma transversalidade no conceito de periferização que perpassa o caráter disciplinar e estanque que nelas estão presentes. A caracterização indistinta que engloba todas as frações do território da cidade que têm baixa renda diferencial, segundo os autores citados, "[...] ganha maior precisão e vincula, concreta e objetivamente, a ocupação do território urbano à estratificação social" (Bonduki \& Rolnik, 1982, p. 173).

A morfologia urbana de Recife, dada a sua singular dimensão territorial entrecortada por rios e mangues e aflorações de morros e aclives que limitam o uso e a produção do espaço e intensificam a verticalização predial, sugere que a valorização imobiliária conduz a um processo de gentrificação que deságua em uma suburbanização típica, a qual alcança e hierarquiza os bairros onde a renda diferencial é gradualmente mais baixa. Assim, torna-se bastante elucidativa a explicitação enunciada por Smith (2007, p. 21): 
O movimento do capital que leva ao desenvolvimento de atividades industriais, comerciais, residenciais e recreacionais nas áreas suburbanas resulta em uma mudança recíproca dos níveis de renda da terra nas áreas centrais e nas áreas suburbanas. Enquanto o preço da terra nas áreas suburbanas eleva-se com a proliferação de novas construções, o preço relativo da terra nas áreas centrais cai. Cada vez menores quantidades de capital são canalizadas para a manutenção e restauração dos edifícios localizados na área central. Isto resulta naquilo que denominamos um diferencial (rent gap) entre a atual renda da terra capitalizada pelo uso presente (deteriorado) e a renda da terra potencial que poderia ser capitalizada pelo "mais elevado e melhor" uso da terra (ou, ao menos, comparativamente "mais elevado e melhor" uso), em virtude da sua localização centralizada.

A leitura de Smith permite estabelecer ilações que se ajustam às economias em desenvolvimento, na medida em que, entre os fatores por ele elencados como deflagradores de processos de gentrificação, avulta a questão da queda na taxa de lucro e os movimentos cíclicos do capital financeiro e produtivo internacional. Esses aspectos aparecem nos trabalhos de Rosenthal (2008) e Rosenthal \& Helsley (1994), os quais consideram a mobilidade residencial um fenômeno fundamentalmente de elite, em que as famílias com maior renda têm a prerrogativa de escolha dos locais que consideram melhores para residir. Essas escolhas, ao longo do tempo, vão estabelecendo processos de atração e repulsão em determinados locais da cidade, o que vai estabelecer ciclos urbanos. A atração das famílias mais abastadas redunda em um processo de aumento sistemático dos preços e, consequentemente, do valor dos tributos e impostos. Então, as famílias com menor renda tendem a buscar locais mais distantes, seja por não possuírem meios de se manter no local, seja pela condição dos proprietários que se aproveitam de uma valorização na venda de seus imóveis.

Abramo (2009) considera que esses movimentos tendem a gerar convenções urbanas, ou seja, conceitos socialmente aceitos acerca das características de vizinhança dos locais da cidade. Estudos realizados em Recife apontaram especificamente as restrições espaciais (mangues, alagadiços e morros) e a pequena área do seu território $\left(219 \mathrm{~km}^{2}\right)$ como fatores de gentrificação (mudanças imobiliárias) em bairros de Recife que produzem tipologias distintas no fenômeno da suburbanização (Leão \& Brito, 2012).

0 primeiro caso é consistente com a descrição elaborada por Smith (2007), que produz o rent gap como consequência do menor atrativo da renda da terra em espaços degradados (bairros Recife e Santo Antônio) em relação à terra potencial da periferia que poderia "ser capitalizada pelo mais elevado e melhor uso da terra". No contexto atual, a presença concertada do poder público e dos stakeholders tem contribuído para atenuar um dos aspectos perversos da gentrificação, que é a degradação dos espaços urbanos, por meio da requalificação, ressignificação e reestruturação de seus usos para a sociedade local. Há que se ressaltar a necessidade de mediação de variados conflitos surgidos entre os atores sociais (produtores imobiliários, poder público, movimentos populares, consumidores etc.) em torno das suas diversas demandas, delineando uma matriz de solução complexa. A quase inelasticidade de oferta de solo urbano é um fator crítico.

A ela são somados outros fatores agravantes, tais como: marcos regulatórios restritivos (Lei dos 12 bairros) de certas áreas para a ação imobiliária e o estoque de imóveis centenários degradados e com impedimentos legais de uso (débitos fiscais, conflitos de herança, propriedades da Santa Casa de Misericórdia etc.). Os mencionados óbices mostram-se como fatores inibidores dos esforços envidados pela gestão pública e pelo empreendedorismo urbano no sentido de ressignificar espaços que poderiam reduzir as tensões especulativas produzidas nas arenas de disputas pelo uso do território do município.

O segundo caso se divide em duas ocorrências: i) da contínua valorização imobiliária de alguns espaços urbanos historicamente valorizados e densamente habitados - que também decorre de uma métrica espacial que implica a limitação da oferta de terra para a obtenção de renda capitalizada, mas que se equaciona e elimina a queda do lucro, por meio de uma estratégia utilizada pelos agentes imobiliários denominada verticalização construtiva de imóveis para habitação, lazer e negócios; e ii) da eleição de áreas limítrofes a bairros da cidade destinados aos ditames da mudança imobiliária (gentrificação), em que a suburbanização e os diferenciais de renda se inserem ao processo de reestruturação urbana. Assim, pode-se ajuizar que o 
fenômeno da gentrificação em Recife se exprime em uma condição de nonsense quando cotejado com os exemplos exitosos (apesar da provável pecha de serem excludentes) de cidades norte-americanas e inglesas, nas quais as características presentes no conceito de enobrecimento dessas localidades são parcialmente verificáveis em uma cidade de capitalismo periférico, como é o caso de Recife.

A referida parcialidade se torna evidente quando se percebe que os esforços direcionados para a recuperação e a ressignificação de áreas degradadas e o redirecionamento de suas funções socioeconômicas se realizam diante de uma constatação de incompletude. Isso se dá por causa de a integralidade das estratégias de ação concebidas no curso do policy-making esbarrar em uma conjunção de óbices. Em geral, referem-se a marcos regulatórios (atuação rigorosa do IPHAN Instituto do Patrimônio Histórico e Artístico Nacional, dívidas tributárias, heranças, sucessões, processos judiciais, entre outros) e a conflitos de interesses entre os agentes econômicos envolvidos, resultando em embates que, em alguns casos, ganham uma dimensão nacional. Como exemplos recentes citam-se os embates ocorridos em toda a fase de implantação do Parque Dona Lindu (bairro Boa Viagem) e o emblemático projeto da construtora Moura Dubeux para o Cais José Estelita (bairro Recife), que gerou o polêmico movimento popular "Ocupe Estelita" em oposição ao projeto "Novo Recife" de interesse da Prefeitura Municipal.

Outro fator destacado por Smith (2007) se refere ao processo de desindustrialização e crescimento da economia terciária, o qual, embora seja inerente aos processos de mudança imobiliária observados em várias capitais brasileiras, no caso de Recife não se evidencia como um componente preponderante na definição de uma gentrificação perfilada aos moldes da observada em países de capitalismo avançado, como sugere Smith. Isso porque Recife, historicamente, sempre se comportou como uma cidade eminentemente rentista e caracteristicamente assentada na economia terciária, mas não chegou a ser, de forma significativa, uma cidade industrial, de tal modo que uma desindustrialização não se evidencia como fator determinante para estabelecer uma gentrificação com a totalidade dos fatores perfilados por Smith (2007). A Tabela 1 evidencia a baixa participação do setor secundário na formação dos PIBs metropolitano e recifense.
Entretanto, em relação ao crescimento da economia terciária, há que se considerar a peculiaridade efetivamente observada nesse crescimento, no que se refere ao fato de que houve uma inequívoca mudança no perfil do setor, haja vista que grande parte da atividade mercantil/rentista se concentrava na função exportadora desempenhada pelo Porto do Recife, ao viabilizar o corredor de exportações do açúcar e os serviços que davam apoio ao desenvolvimento da atividade açucareira (serviços bancários, despachantes, corretores de bolsa de mercadorias, comércio de máquinas e equipamentos para usinas e para a cultura agrícola da cana de açúcar). Com a perda da atividade portuária (transferida para o Porto de Suape, no município de Ipojuca) e com a expressiva queda das exportações de açúcar (que inibiu e eclipsou serviços correlatos), o que se observou foi uma mudança nesse perfil de economia terciária, na medida em que o setor de serviços se orientou para transformar Recife em um relevante polo médico para a região Nordeste e em um importante polo de tecnologia voltado para a produção de softwares e aplicativos, o qual se consolidou como um dos mais importantes do país.

Smith (2007) também salienta um fator que, de modo irrefutável, impõe padrões de mudança imobiliária e de necessidade contínua de reestruturação urbana, e talvez se constitua como o mais importante entre os fatores por ele citados, embora, como já mencionado no início dessa fundamentação teórica, seja difícil, dada a imbricação existente entre eles, posicioná-lo como tal, qual seja: as mudanças demográficas e nos padrões de consumo. Nesse sentido, o autor destaca o grande contexto de mudanças ocorridas a partir do envelhecimento da população do pós-guerra

Tabela 1 - Composição percentual do PIB da RMR e de Recife

\begin{tabular}{crrrr}
\hline DISCRIMINAĈ̣AO & \multicolumn{1}{c}{1970} & \multicolumn{1}{c}{1980} & \multicolumn{1}{c}{1995} & \multicolumn{1}{c}{$\mathbf{2 0 1 0}$} \\
\hline RMR & 100,00 & 100,00 & 100,00 & 100,00 \\
AGRICULTURA & 7,00 & 4,00 & 0,00 & 0,61 \\
INDÚSTRIA & 24,00 & 27,00 & 26,90 & 27,78 \\
SERVIICOS & 69,00 & 68,00 & 73,10 & 74,61 \\
RECIFE & 100,00 & 100,00 & 100,00 & 100,00 \\
AGRICULTURA & 0,04 & 0,03 & 0,04 & 0,06 \\
INDÚSTRIA & 19,98 & 26,05 & 25,70 & 17,32 \\
SERVIC̦OS & 79,98 & 73,92 & 74,26 & 82,62 \\
\hline
\end{tabular}

Fonte: CONDEPE/FIDEM (2010). 
(geração baby boom), a ascensão massiva da mulher no mercado de trabalho e o surgimento de um novo padrão de família constituído de uma ou duas pessoas (estilo de vida solteiro urbano). Bem a propósito, a busca de uma nova formatação para o perfil mercantil rentista que Recife vem processando parece ser consentânea com as mudanças de padrão imobiliário a que alude Smith. Isso mostra que está imprimindo um caráter mais seletivo aos mecanismos que formam a sua renda, tendo em vista que o seu mercado de trabalho vem se redesenhando sob os auspícios de uma mão de obra que, dia a dia, vem se adaptando às necessidades de um terciário superior que se consolida com os polos tecnológico e médico, fato que implica mudanças nos padrões de consumo e de renda.

Todavia, embora tais ocorrências estejam, aparentemente, associadas a um processo gradual de mutação nas escolhas individuais, o autor chama a atenção para a visão reducionista que essa conclusão apressada produz, ao acrescentar que a reestruturação urbana a que o mundo atual assiste vai muito mais além de uma solitária e simplista mudança imobiliária (ou reabilitação residencial).

A adoção de um périplo teórico construído em termos de um diapasão quase que monocórdico de referências e balizamentos para o presente artigo, cuja base argumentativa se apoia quase que em um único autor, teve o propósito de permitir um foco interpretativo do fenômeno da gentrificação observado em Recife, a partir da análise de fatores de mudança imobiliária que, na visão do criador do termo e estudioso do fenômeno, estavam ocorrendo, há bem pouco tempo, em nações de capitalismo avançado. Nesse sentido, ao confrontar as mudanças ocorridas alhures com as ocorridas no lócus recifense (inicialmente em Boa Viagem), pode-se perceber que a realidade do aldeamento global produz, com poucas diferenciações, uma reestruturação urbana extremamente sensível aos mesmos fatores interferentes observados nos Estados Unidos e na Europa, ainda que, às vezes, seguindo uma lógica inversa.

\section{Apresentação e discussão dos resultados}

Os dados são apresentados e discutidos por meio de uma apresentação descritiva inicial, de modo a justificar a escolha do bairro abordado. Posteriormente, são apresentados os resultados da regressão linear e das discussões propostas no trabalho.

Como demonstra o Gráfico 1, as vendas de imóveis em Recife apresentaram índices consistentes de crescimento e mantiveram essa tendência até o período estudado. Pode-se perceber a pujança do mercado habitacional, principalmente a partir do ano de 2006.

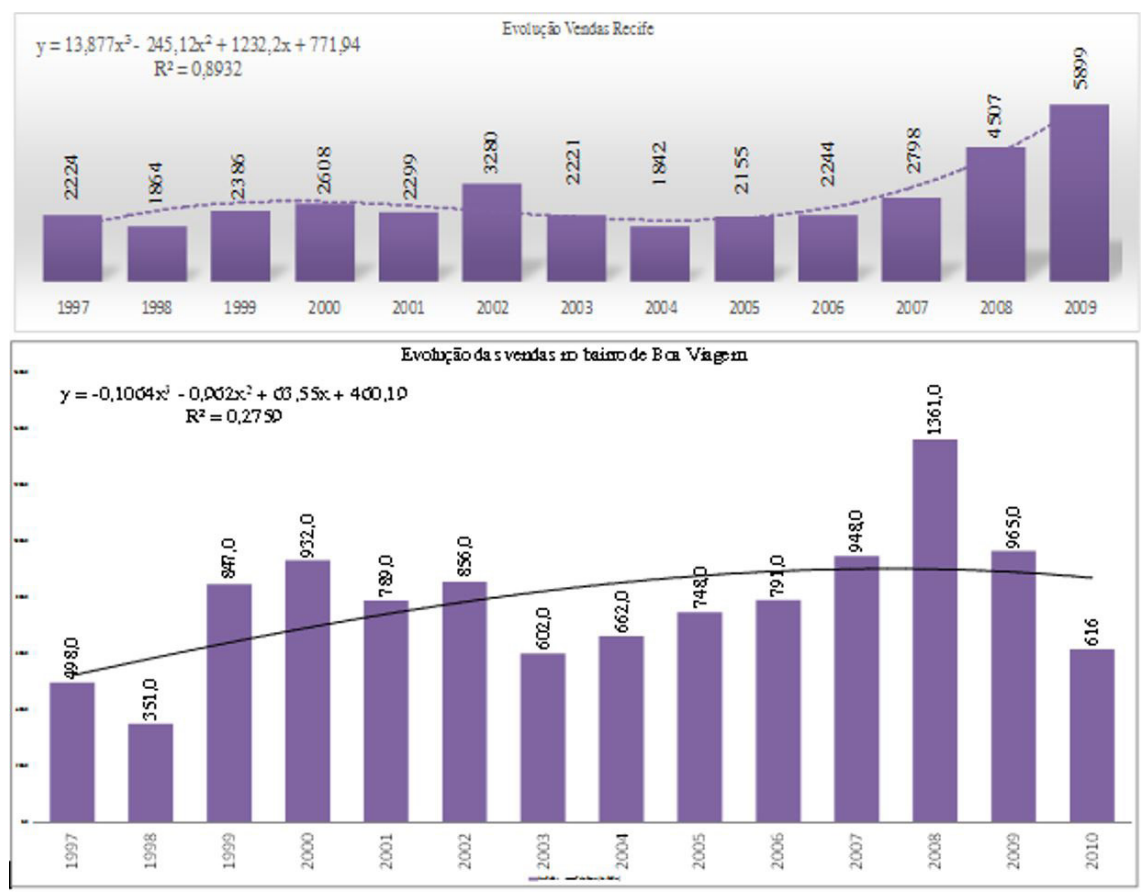

Gráfico 1 - Comparativo da evolução das vendas de imóveis em Recife-PE (1997 a 2009) e no bairro Boa Viagem (1997 a 2010) Fonte: FIIPE (2014). 
Aplicou-se à série uma linha de tendência, com ajuste polinomial de terceira ordem, visto que o comportamento do mercado imobiliário apresenta momentos de crescimento e decrescimento. Observou-se que houve um arrefecimento do processo de crescimento do mercado, o que pode estar relacionado com o fim do ciclo de crescimento econômico no país, desde o ano de 2012. O coeficiente da variável de terceira ordem apresentou valor próximo de zero, negativo; e o de segunda ordem, valor positivo e baixo, próximo de zero; já o coeficiente da variável de segunda ordem apresentou valor negativo e alto. Desse modo, a curva tende a crescer a taxas cada vez menores. Se a equação é derivada, temos a equação da taxa de variação das unidades vendidas, como demonstra a Equação 1.

$\frac{d y}{d x}=-0,1064 \cdot x^{2}-0,962 \cdot x+63,55$

Como a variável $x$ representa o ano da ocorrência da previsão, poder-se-ia estimar uma tendência de queda na variação de vendas de imóveis ao longo dos próximos anos. Na projeção apresentada no Gráfico 1 , percebe-se que, após avançar 30 meses do período utilizado para obter a distribuição, a curva apresenta tendência de estabilidade. 0 bairro Boa Viagem foi um dos principais vetores desse processo de crescimento.

Boa Viagem representava, segundo dados da FIEPE (2014), quase $20 \%$ das vendas de imóveis de Recife. Trata-se de um bairro de classe média e alta, mas com alguns espaços ocupados por comunidades pobres em habitações precárias. A ação do mercado habitacional acabou por intensificar o processo de deslocamento dessas populações mais pobres para outros bairros. 0 bairro possui uma área pouco maior do que $7 \mathrm{~km}^{2} \mathrm{e}$ uma população de 122.000 (cento e vinte e dois mil) habitantes, ou seja, uma concentração urbana com

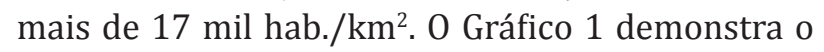
crescimento das vendas no bairro.

Usando a mesma metodologia de tratamento aplicada à cidade de Recife, obteve-se uma equação de tendência polinomial de terceira ordem. 0 coeficiente de terceira ordem apresentou valor positivo e próximo de 0,$1 ; 0$ de segunda ordem, valor positivo e alto $(635,98)$; o de primeira ordem, negativo e alto $(1.267 .425,13)$; e a constante, positivo e igual a $841.898 .587,83$. Procedendo à derivada da função, obtém-se a função representativa da taxa de variação das vendas para o bairro (Equação 2):

$$
\frac{d y}{d x}=13,87 \cdot x^{2+} 245,12 \cdot x+771,94
$$

A taxa de variação denota uma tendência de queda nas vendas para o bairro, como demonstra a projeção gerada no próprio gráfico, em que o período apresenta valores menos significativos para as vendas de imóveis residenciais no bairro. Esse fenômeno era esperado, visto que a própria limitação territorial do bairro tende a levar a um gradual processo de esgotamento dos espaços para a produção imobiliária residencial.

É importante ressaltar que, ainda havendo uma sensível diminuição nos índices de vendas do bairro, este ainda é o mais representativo em termos quantitativos no contexto do mercado local. 0 bairro apresentou um processo de gradual mudança nas características demográficas, resultado da repulsão das populações mais pobres ao longo do tempo, causada pelo aumento dos impostos e do custo de vida na localidade. Um primeiro aspecto a se observar dessas mudanças é a evolução populacional, que passou de 88 mil para 122 mil desde 1991 até 2010, implicando um incremento de 38,63\% de pessoas vivendo no local (Gráfico 2).

Se comparado ao crescimento populacional de Recife, que foi de 17,35\% no mesmo período, percebe-se que houve um deslocamento populacional significativo para o bairro. Como as construções predominantes no bairro são de um padrão vertical, voltado para as classes média e alta, pode-se inferir que esse deslocamento teve o predomínio de pessoas de classe média e alta, e isso modificou gradualmente as características do bairro. 0 Gráfico 2 apresenta a evolução populacional da cidade.

Em relação à faixa etária, observa-se que o bairro apresentou mudanças no perfil do morador, principalmente em relação à atração de habitantes com maior poder aquisitivo, o que representou um aumento significativo nos padrões de renda, educação e faixa etária.

Os dados dos Censos de 1991 e 2010, relativos ao bairro Boa Viagem, mostram que a população jovem, de até 24 anos de idade, diminuiu de 40.419 habitantes em 1991 para 37.630 em 2010. Ainda que seja uma diminuição pouco expressiva, pode ser um indicativo de envelhecimento do bairro. A população acima de 65 anos representava 5.057 pessoas (em 1991), enquanto, em 2010, só os habitantes de 70 anos ou mais já eram 9.644. Se for levada em consideração a população de 60 anos ou mais, esse número passa para 20.275 habitantes. Esses indicadores estão relacionados, posto que há uma correlação positiva entre idade e renda no Brasil. 


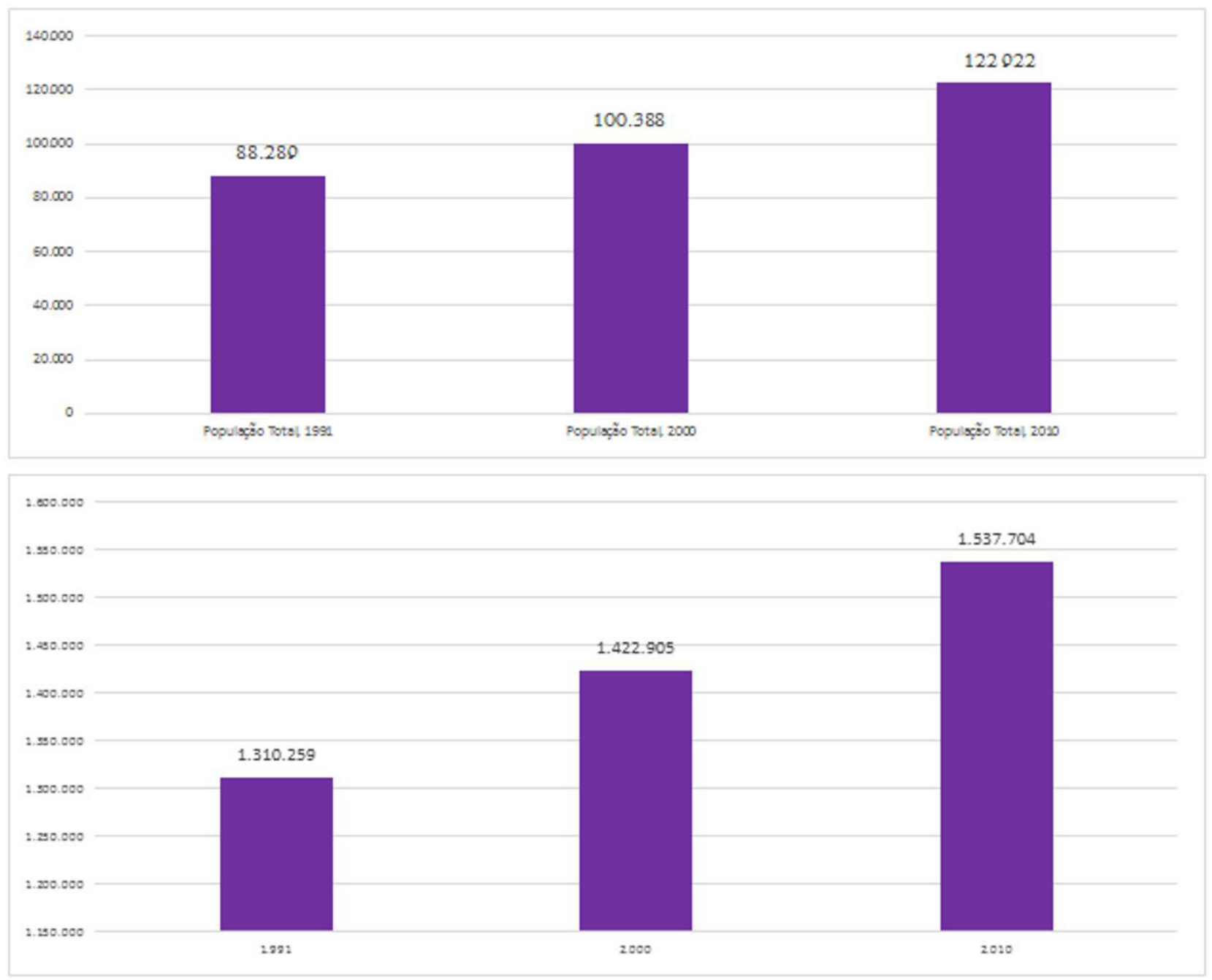

Gráfico 2 - Evolução populacional do bairro de Boa Viagem e em Recife, respectivamente Fonte: Censo IBGE (1991, 2000, 2010a, 2010b).

Quanto aos aspectos educacionais, cabe ressaltar que, conforme dados do Censo (IBGE, 2010a, 2010b), não há analfabetos acima de 5 anos de idade, bem como a predominância é de $66 \%$ de brancos, outro indicador que também está relacionado com o nível de renda.

Demonstram também que a renda média do chefe do domicílio, em 1991, era de R\$2.586,95, e a renda média do chefe de domicílio para Recife era de $\mathrm{R} \$ 805,86$. Ou seja, a média do bairro era 3,21 vezes a renda média da cidade. Em 2010, com a introdução de um novo critério de estimação de renda, foi divulgada a renda média familiar (não mais a do chefe do domicílio), o que gera uma diferença que impossibilita a comparação direta dos valores, mas, proporcionalmente à renda média da cidade, em 2010 a renda do bairro Boa Viagem representava
4,30 vezes a renda média da cidade. Ou seja, o bairro apresentava renda de $\mathrm{R} \$ 4.900,00$, enquanto a cidade, R\$ $1.140,00$. Essa é outra indicação de que houve um gradual processo de repulsão das populações mais pobres com a chegada dos empreendimentos habitacionais de classe média e alta no bairro. As mudanças nos indicadores são reflexos de um processo de gentrificação que acelerou o incremento da atividade imobiliária (mudança imobiliária) no bairro. As populações mais pobres podem ter buscado as cidades da RMR (Região Metropolitana do Recife), que apresentam níveis de preços menores, tanto em relação a serviços quanto aos preços dos imóveis.

0 acesso ao saneamento básico é outro aspecto tratado como forma de determinar as condições socioeconômicas de uma localidade. Quando se comparam os valores do índice de saneamento de 
Boa Viagem com os vigentes em Recife, percebe-se que, embora a cidade tenha apresentado valores consideráveis de melhoria, o bairro de Boa Viagem demonstrou valores superiores, consolidando a hipótese de que houve um processo de seleção natural fundamentada em condições socioeconômicas, o que, de algum modo, aproxima a ideia de gentrificação apresentada por Smith (2007) e por outros autores.

Esse fenômeno foi observado por Smolka (1987) em estudo realizado na cidade do Rio de Janeiro. $\mathrm{O}$ autor identificou que houve um processo de migração dentro da cidade, entretanto os moradores, mesmo em situação econômica superior, tendem a buscar espaços mais valorizados, que resguardem, de alguma maneira, as características socioeconômicas a que eles pertencem, como se houvesse um processo de transição econômica que ainda não chegou a se consolidar como uma transformação social. Nesse sentido, Leão \& Brito (2011) constataram que as mudanças, muitas vezes, ocorrem na direção de uma área mais valorizada próxima à área (ao bairro) de origem.

Como mostra a Tabela 2, quase a totalidade dos domicílios do bairro apresentou instalações sanitárias (sistema de coleta ou pelo menos uma fossa séptica), 99,86\% em 2010, enquanto Recife teve 99,48\% dos domicílios. Logicamente que um bairro que já apresenta índices altos de saneamento tende a apresentar valores incrementais menores em relação a outros bairros em situação pior. Quanto à coleta de lixo, pode-se fazer uma análise semelhante, pois Recife tem $97,86 \%$ de domicílios atendidos por um sistema de coleta, e Boa Viagem, 99,5\%. Ainda que a diferença seja numericamente pequena, em uma cidade que possui um sistema de coleta que abarca

Tabela 2 - Dados referentes ao saneamento básico no bairro Boa Viagem

\begin{tabular}{cccc}
\hline $\begin{array}{c}\text { Percentual de pessoas que vivem em } \\
\text { domicílios com instalação sanitária }\end{array}$ & 1991 & $\mathbf{2 0 0 0}$ & $\mathbf{2 0 1 0}$ \\
\hline $\begin{array}{c}\text { Boa Viagem } \\
\text { Recife }\end{array}$ & 95,92 & 98,78 & 99,86 \\
93,01 & 97,44 & 99,48 \\
\hline $\begin{array}{c}\text { Percentual de pessoas que vivem em } \\
\text { domicílios urbanos com serviço de } \\
\text { coleta de lixo }\end{array}$ & 1991 & $\mathbf{2 0 0 0}$ & $\mathbf{2 0 1 0}$ \\
\hline $\begin{array}{c}\text { Boa Viagem } \\
\text { Recife }\end{array}$ & 91,95 & 98,75 & 99,50 \\
\hline
\end{tabular}

Fonte: Censo IBGE (1991, 2000, 2010a, 2010b). quase todo o seu território, uma pequena diferença percentual pode ser considerada relevante.

Esses fatores em conjunto demonstram que o bairro vem de fato passando por um processo de mudança, pois, além de um incremento de população de quase $39 \%$ (desde 1991), como mostrado no Gráfico 2, essa população não atuou como fator de minimização dos valores dos indicadores socioeconômicos do bairro; pelo contrário, aumentou-os.

O número de domicílios particulares permanentes também aumentou percentualmente, como mostra ao Gráfico 3. Isso está relacionado com o tipo de morador que veio para o bairro ao longo do tempo. Esse dado relaciona-se com a presença significativa de idosos, que, em geral, já criaram seus filhos, não necessitando de espaços tão grandes, mais interessados em usufruir da infraestrutura do bairro. Em geral, essas pessoas apresentam níveis de renda mais elevados.

Os aspectos apresentados se refletiram no valor do metro quadrado no bairro, o que estabelece uma conexão com a gentrificação, visto que o processo se dá, em parte, pelo aumento sistemático dos preços da terra, aumentando o valor dos impostos e inviabilizando a vida para as famílias menos abastadas. A partir de dados do ITBI (Imposto sobre Transmissão de Bens Imóveis), fornecidos pela Prefeitura da cidade de Recife em 2011, em que o valor médio do metro quadrado em Boa Viagem (avaliado em 2010) era de $\mathrm{R} \$ 3.750,00$, enquanto o valor em Recife era de $\mathrm{R} \$ 1.587,00$, observou-se que há uma diferença de $85 \%$ em favor de Boa Viagem. De acordo com a mesma base

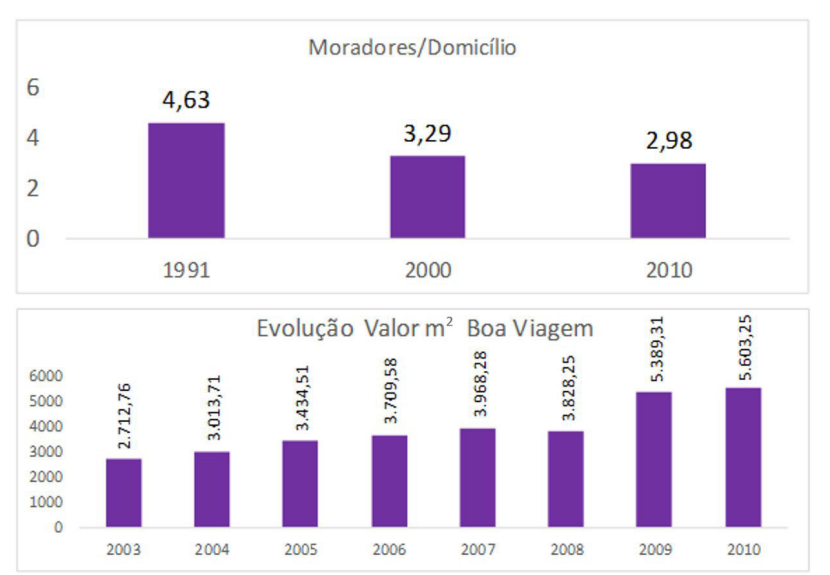

Gráfico 3 - Evolucũão do número de moradores por domićilio em Boa Viagem e evolução do valor do metro quadrado Fonte: Elaborado pelos autores baseado nos dados do Censo IBGE (1991, 2000, 2010a, 2010b). 
de dados, o valor médio do metro quadrado era de $\mathrm{R} \$$ 2.270,00 em 2003, ou seja, a valorização no período foi de $65,20 \%$ em 7 anos, representando uma taxa geométrica de crescimento de 1,0743 (7,43\% a.a.), como mostra o Gráfico 3.

Culminando essa evidenciação de resultados e inferências, optou-se por uma análise correlacional na qual os dados da Tabela 3 (referentes ao número de moradores por domicílio e valor do metro quadrado) sugerem uma correlação inversa entre as referidas séries de dados, reforçando uma das principais características da gentrificação, que é o pressuposto parcialmente excludente, em termos qualitativos, do enobrecimento dos espaços urbanos pela substituição do elemento humano em função de fatores como renda e educação.

0 resultado dessa análise correlacional (que este estudo está denominando função enobrecimento), a qual tomou a variável "moradores por domicílio" como variável dependente, pelo fato de ser influenciada pelo "valor do metro quadrado", produziu uma equação do tipo polinomial de segundo grau, cuja curva de tendência não possui ponto de inflexão, o que significa que as respectivas séries de dados mantiveram, ano a ano, taxas decrementais (moradores por domicílio) e incrementais (preço do metro quadrado), em ritmo contínuo, ou seja, sem altercações, em ambos os casos. Em que pese a concavidade voltada para cima (como sugere a tendência polinomial), a relação se apresenta como uma função decrescente, indicando a propensão declinante da variável "moradores por domicílio" em relação à propensão crescente da variável "preço do metro quadrado" no tempo. A derivada de primeira ordem está expressa a seguir e evidencia a taxa de variação de y (variável "moradores por

Tabela 3 - Análise de regressão "número de moradores por domićilio versus preço do $\mathrm{m}^{2 \prime \prime}$

\begin{tabular}{cc}
\hline \multicolumn{2}{c}{ ESTATÍSTICA DE REGRESSÃo } \\
\hline R múliplo & 0,795632 \\
R-quadrado & 0,63303 \\
R-quadrado ajustado & 0,58303 \\
Erro padrão & 1751,284 \\
Observacọ̃es & 21 \\
\hline
\end{tabular}

Fonte: Elaborada pelos autores baseado nos dados do Censo IBGE (1991, 2000, 2010a, 2010b). domicílio") em relação a x (variável "preço do metro quadrado") (Equação 3):

$\frac{d y}{d x}=0,0000004 \cdot x-0,0016$

em que: $\mathrm{F}^{\prime}(\mathrm{X})<0$.

0 coeficiente de determinação, identificado na análise de correlação, tem expressivo poder de explicação que a variável independente exerce sobre a variável dependente (moradores por domicílio), refletido por um coeficiente de determinação $\left(R^{2}\right)$ de 0,9823 , ou seja, 98,23\%. Tal representatividade estatística pode ser traduzida, levando-se em conta a extensão da série de dados (quase duas décadas de observação), no reconhecimento de que, subjacente ao comportamento evolutivo da variável "preço do metro quadrado", a variável renda atua de modo a impor padrões gentrificadores e de mudança imobiliária por causa da evolução das convenções urbanas e sociais influenciadas ou orquestradas pelos agentes imobiliários.

Nesse sentido, parece ser razoável aceitar que o "número de moradores por domicílio" seja uma determinação da variável "preço do metro quadrado", a qual, por sua vez, é determinada pela variável "renda". Parece ser correto aceitar que o caráter declinante do "número de moradores por domicílio" seja influenciado pelos fatores de mudança imobiliária, apontados por Smith (2007). Desse modo, aspectos, tais como revitalização de espaços urbanos, inserção da mulher no mercado de trabalho, controle da natalidade, externalidades de vizinhança, atrativos hedônicos, estilo de vida solteiro urbano e envelhecimento da geração baby boom, entre outros, parecem confluir para a aceitação da ideia de "áreas enobrecidas" ou de "bem-nascidos", em oposição à ideia de áreas suburbanizadas.

\section{Considerações finais}

As análises efetuadas no transcorrer deste trabalho permitem concluir que a ocorrência de padrões associados à incipiente ideia de reestruturação urbana, caracterizada por mudanças imobiliárias que atestam os fenômenos da gentrificação e da suburbanização, tais como analisados por Smith (2007), confirmam-se neste estudo de caso para o município de Recife, do qual o bairro Boa Viagem 
pontifica como o primeiro de uma série de estudos que os autores pretendem realizar com os demais bairros da municipalidade.

Vale acrescer que as conclusões e os resultados obtidos delineiam para Boa Viagem uma realidade que o consolida, com evidências sobejas, como um lócus urbano que se enobrece, não se questionando as externalidades econômicas positivas ou negativas que tal enobrecimento produz. No tocante ao fenômeno da suburbanização, resultante do processo de gentrificação, visto que decorre da substituição e do deslocamento da população para lócus periféricos, embora não tenha sido objeto de análise direta neste estudo, ele fica evidenciado por meio da mudança populacional e pela concentração de renda média crescente, demonstradas para o bairro Boa Viagem. Entretanto, faz-se necessário, para a compreensão de um mosaico de imbricações que envolvem os fenômenos tratados, analisar a suburbanização de forma mais direta, a partir dos bairros que se configuram como receptáculos da periferização. Parece ser indissociável a necessidade de entender as tendências de uma reestruturação urbana que se conflita com os antagonismos produzidos pelas gentrificação, suburbanização, requalificação e degradação dos lócus urbanos. Caminhar nesse sentido se coloca como uma diretriz para novos estudos.

Cabe inferir, embora não sendo o objetivo central do trabalho, que a ação do poder público municipal se constitui em variável interveniente, visto que representa possibilidade de segmentação e tipificação dos espaços urbanos por meio de processos regulatórios que podem atuar como restritores ou propulsores da atividade imobiliária municipal. O caso de Boa Viagem historicamente apresentou condições regulatórias pouco restritivas, o que explica, em parte, a decisão dos agentes imobiliários em investir no bairro, em detrimento de outras áreas potencialmente viáveis.

\section{Referências}

Abramo, P. (2009). A cidade com-fusa: mercado e a produção da estrutura urbana nas grandes cidades. In Anais do XIII Encontro da ANPUR (pp. 25-53). Belo Horizonte: ANPUR. Agência Estadual de Planejamento e Pesquisas de Pernambuco - CONDEPE/FIDEM. (2010). Composição setorial do Valor Adicionado Bruto (VAB). Recife: CONDEPE/FIDEM.
Bonduki, N., \& Rolnik, R. (1982). Periferia da Grande São Paulo: reprodução do espaço como expediente de reprodução da força de trabalho: a produção capitalista da casa (e da cidade) do Brasil industrial (pp. 117-154). São Paulo: Alfa-Ômega.

Federação das Indústrias do Estado de Pernambuco FIEPE. (2014). Índice de velocidade de vendas: Recife e região metropolitana. Recife: FIEPE. Recuperado em 22 de dezembro de 2014, de http://www1.fiepe.org.br/fiepe/ arquivos/politica_industrial_FIEPE.pdf

Glass, R. (2013). Urban sociology in Great Britain. In R. E. Pahl (Ed.), Readings in urban sociology: readings in sociology (pp. 47). Oxford: Pergamon Press.

Instituto Brasileiro de Geografia e Estatística - IBGE. (1991). Censo demográfico. Rio de Janeiro: IBGE. Recuperado em 11 de agosto de 2017, de www.ibge.gov.br/home/estatistica/ populacao/censo1991

Instituto Brasileiro de Geografia e Estatística - IBGE. (2000). Censo demográfico. Rio de Janeiro: IBGE. Recuperado em 11 de agosto de 2017, de www.ibge.gov.br/home/estatistica/ populacao/censo2000

Instituto Brasileiro de Geografia e Estatística - IBGE. (2010a). Censo demográfico. Rio de Janeiro: IBGE. Recuperado em 11 de agosto de 2017, de www.ibge.gov.br/home/estatistica/ populacao/censo2010

Instituto Brasileiro de Geografia e Estatística - IBGE. (2010b). Aglomerados subnormais: informações territoriais. Rio de Janeiro: IBGE.

Jacobs, J. (2011). Morte e vida de grandes cidades (3. ed.). São Paulo: WMF Martins Fontes.

Jager, M. (1986). Class definition and the esthetics of gentrification: Victoriana in Melbourne. In P. Williams, \& N. Smith (Eds.), Gentrification of the city (pp. 78-91). Boston: Allen \& Unwin.

Leal, S. (2003). Fetiche da participação popular: novas práticas de planejamento, gestão e governança democrática no Recife, Brasil. Recife: Editora CEPE.

Leão, F. S., Jr., (2012). Dinâmica espacial do mercado habitacional formal na cidade do Recife-PE (Tese de doutorado). Universidade Federal de Pernambuco, Recife.

Leão, F. S., Jr., \& Brito, C. S. (2011). Espacialização urbana fundamentada em renda um estudo de caso na cidade do Recife-PE. Revista HUM@NAE, 5(1), 1-18. 
Leão, F. S., Jr., \& Brito, C. S. (2012). Territórios simbólicos da cidade: as estratégias do capital imobiliário na consolidação de novas formas de morar. Revista HUM@NAE, 6(1), 1-20.

Paiva, C. C. (2007). A diáspora do capital imobiliário, sua dinâmica de valorização e a cidade no capitalismo contemporâneo: a irracionalidade em processo (Tese de doutorado). Universidade Estadual de Campinas, Campinas.

Recife. (2001, 1 de dezembro). Lei Municipal no 16.719, de 30 de novembro de 2001. Cria a Área de Reestruturação Urbana - ARU, composta pelos bairros Derby, Espinheiro, Graças, Aflitos, Jaqueira, Parnamirim, Santana, Casa Forte, Poço da Panela, Monteiro, Apipucos e parte do bairro Tamarineira, estabelece as condições de uso e ocupação do solo nesta área (Lei dos Doze Bairros). Recife: Diário Oficial do Estado de Pernambuco.

Rosenthal, S. S. (2008). Old homes, externalities, and poor neighborhoods: a model of urban decline and renewal. Journal of Urban Economics, 63(3), 816-840. http://dx.doi. org/10.1016/j.jue.2007.06.003.

Rosenthal, S. S., \& Helsley, R. W. (1994). Redevelopment and the urban land price gradient. Journal of Urban Economics, 35(2), 182-200. http://dx.doi.org/10.1006/juec.1994.1012.
Silva, G. P., Fereti, S. F., \& Sette, E. (2008). Gentrificação, e políticas de revitalização nos centros históricos no Brasil: processos que levam ao déficit habitacional. Revista de Políticas Públicas, 12(2), 83-91.

Smith, N. (2006). A gentrificação generalizada: de uma anomalia local à "regeneração" urbana como estratégia urbana global. In C. Bidou-Zachariasen (Ed.), De volta à cidade: dos processos de gentrificação às políticas de "revitalização" dos centros urbanos (pp. 58-87). São Paulo: Annablume.

Smith, N. (2007). Gentrificação, a fronteira e a reestruturação do espaço urbano. GEOUSP: Espaço e Tempo, (21), 15-31. http:// dx.doi.org/10.11606/issn.2179-0892.geousp.2007.74046.

Smolka, M. O. (1987). O capital incorporador e seus movimentos de valorização. Cadernos IPPUR, 2(1), 41-78.

Zukin, S. (2000). Paisagens urbanas pós-modernas: mapeando cultura e poder. In A. Arantes (Ed.), O espaço da diferença. Campinas: Papirus.

Recebido: Ago. 30, 2017

Aprovado: Abr. 05, 2018 